\title{
A UNIDADE E A MULTIPLICIDADE NA COSMOLOGIA DE JUDÁ ABRAVANEL
}

\author{
Daniel Rodrigues de Assis Martins \\ Universidade Federal de São Paulo
}

Resumo: Um tema de grande importância apresentado no livro de Judá Abravanel, Diálogos de Amor, é a sua visão cosmológica, onde o filósofo expressa sua visão da criação. Seguindo a filosofia neoplatônica, o Criador é visto como a suprema unidade. 0 objetivo deste trabalho é entender como são usados na obra os conceitos de unidade e multiplicidade. Na cosmologia de Abravanel, a passagem da unidade para a multiplicidade está presente em tudo o que é criado, mesmo objetos criados por pelo homem. 0 amor é o elo entre todos os seres do cosmos e a explicação da presença do amor em todos os seres é o que orienta a argumentação do texto. A origem do amor é explicada no terceiro e último diálogo. E é neste ponto do texto que Abravanel passa a nos dizer como ocorreu a criação. 0 amor é apresentado como parte da essência Divina e existente desde antes da criação. 0 mundo é gerado quando Deus tem amor por sua própria Beleza e se une com ela. Segundo Abravanel, para que qualquer coisa seja criada é necessária a presença de dois princípios. A criação é uma passagem da unidade para a multiplicidade porque o mundo criado é uma cópia perfeita da Beleza divina, onde as essências de todos os seres do mundo criado estão em unidade. A criação dos corpos do céu pelas inteligências também ocorre pela visão da Beleza e pelo amor à Ela. No mundo material, a inteligência do planeta terra cria todas as espécies através do mesmo processo. Todos os seres da natureza são o resultado da contemplação de suas essências. Essas essências estão em unidade na Alma do Mundo e passam para multiplicidade quando formam os corpos materiais. A alma do mundo cria os humanos da mesma maneira, mas quando contempla a unidade da Beleza divina ela cria o intelecto humano. Dotado de intelecto, o humano é o único capaz de contemplar a beleza das ideias. Quando é criado um objeto artificial por mãos humanas, esta criação é também resultado da passagem da unidade para a multiplicidade, porque ocorre a partir de uma visão intelectual da ideia do objeto. Ao criar o objeto artificial com seu esforço, o homem faz a passagem da unidade da ideia do objeto para a multiplicidade da materialização do mesmo. Mas os humanos também são responsáveis pelo retorno à unidade. Quando o homem vê e ama a beleza expressa em objetos materiais, é importante que ele tenha consciência de que a beleza que ele vê não está na matéria que compõe o objeto, mas sim na ideia que moldou a matéria. Em outras palavras, a beleza nunca está na multiplicidade, mas sim na unidade.

Palavras-chave: Renascença. Neoplatonismo. Cosmologia. Uno. Natureza.

1 Mestrando em Filosofia, bolsista da CAPES. E-mail: ramartins81@gmail.com. 
Unity and multiplicity in Judah Abravanel's cosmology

\begin{abstract}
A central theme presented in Judah Abravanel's book, Dialogues of Love, is his cosmological view. The aim of this work is to understand how the concepts of unity and multiplicity are used in the text. Following the Neoplatonic philosophy, the Creator is seen as the supreme unity. The philosopher expresses in the text his vision of creation. In his cosmology, the passage from unity to multiplicity is present in all that is created, even objects created by man. Love is the link between all beings in the cosmos. The explanation of love's presence in all beings guides the text argumentation. Love's origin is explained in the third and final dialogue. In this point of the text Abravanel tells us how creation occurred. Love is presented as part of the Divine essence and its existence precedes the Creation. The world is generated when God has love for His own Beauty and unites himself with it. According to Abravanel, the creation of anything requires necessarily the presence of two principles. Creation is a passage from unity to multiplicity because the created world is a perfect copy of the Divine Beauty, where all beings' essences of the created world are in unity. The creation of the celestial bodies by the intelligences also occurs because of the vision of Beauty and the love of It. In the material world, the planet earth's inteligence creates all species through the same process. All nature's beings are the result of the contemplation of their essences. These essences are in unity in the World's Soul and pass to multiplicity when they form the material bodies. The World's Soul creates humans in the same way, but when it contemplates the Divine Beauty's unity it creates the human intellect. With his intellect, the human is the only one capable of contemplating the idea's beauty. When an artificial object is created by human hands, this creation is also a result of the passage from unity to multiplicity, because it occurs from an intellectual view of the idea of the object. When man creates the artificial object with his effort, he makes the passage from the object idea unity to the multiplicity of its materialization. But humans are also responsible for the return to unity. When man sees and loves beauty in material objects, it is important that he be aware that the beauty he sees is not in the matter that composes the object, but it is the idea that shaped matter. In other words, beauty is never in multiplicity, but in unity.
\end{abstract}

Keywords: Renaissance. Neoplatonism. Cosmology. One. Nature 
A obra Diálogos de Amor surgiu em Nápoles, na Itália renascentista do século XVI. Judá Abravanel, que ficou mais conhecido como Leão Hebreu, foi um filósofo e médico bastante requisitado pela nobreza da época. Seu pai, Isaac Abravanel, foi tesoureiro em reinos de Portugal, Espanha e Itália, além de um importante exegeta de textos da tradição judaica. Os Diálogos de Amor têm tendência enciclopédica, assim como obras de Marsilio Ficino e Pico Della Mirandola. Para o comentador João Vila-Chã, enquanto Pico e Ficino se esforçaram para conciliar a Academia de Platão ao cristianismo, o esforço de Abravanel é o de fazer tal conciliação com o judaísmo. 0 caráter enciclopédico faz com que o filósofo explique o posicionamento de diversos autores sobre variados assuntos. Porém, podemos dizer, com certeza, que a explicação do cosmos é uma preocupação central. Neste trabalho, trataremos da visão de Abravanel sobre a Criação e sobre a importância dos conceitos de unidade e multiplicidade em sua filosofia.

No texto, as investigações sobre 0 amor são o fio condutor para exposição dos argumentos. Seguindo a tradição platônica, o amor pode ser identificado na obra com o desejo. Mas há divergências com o conceito de amor expresso no Banquete de Platão. No diálogo do mestre da academia, Sócrates é o último a discursar e apresenta o amor como um "daimon", algo que está entre os deuses e os homens. Mesmo no discurso de Erixímaco, que apresenta 0 amor como universal, o amor é mostrado como benigno ou maligno. Para termos uma compreensão mais clara da obra de Abravanel, é importante a compreensão de que 0 amor é visto como 0 movimento no ânimo daquele que vê a beleza. A beleza, por sua vez, "é a graça que, deleitando o ânimo pelo seu conhecimento, o move a amar" (ABRAVANEL, 2001, pg. 265). 
A obra trata-se de um diálogo entre Filon e Sofia, o amante e a amada. Ela não sede as investidas de Filon e busca saber não só se 0 amor dele é verdadeiro, mas também tudo o que ele sabe sobre o amor. Em determinado momento do texto, já no terceiro e último diálogo, ele explica para Sofia qual é a origem do amor no mundo. Para expor tal origem Filon faz um relato da Criação, e fala que o amor já existia na essência da Divindade antes da Criação.

Segundo a personagem, o primeiro amor é aquele do primeiro amante ao primeiro amado. Mas como nesse caso 0 amante e 0 amado são eternos, 0 amor deles também é eterno. 0 primeiro amante é Deus que conhece e quer. 0 primeiro amado, por sua vez, é também o próprio Deus, pois o primeiro amado é a Suma Beleza, que é a Beleza de Deus. Com isso não se quer dizer que Deus deseja a si a mesmo pela existência de qualquer carência n'Ele. Em Deus não faz diferença ser amante e ser amado, pois esta relação intrínseca torna a sua unidade mais perfeita e simples. 0 cognoscente, a coisa conhecida e o conhecimento é uma coisa só n'Ele. Ele é o amante, 0 amado e o próprio amor.

Não podemos conceber esta unidade, porque quando a pura simplicidade de Deus se imprime no nosso espelho intelectivo, produz uma trina reverberação. Nosso intelecto, que está em potência, não pode compreender a Divindade, que excede infinitamente a natureza intelectiva dele. Basta ao nosso espelho intelectivo receber e configurar a imensa essência divina na medida da capacidade da sua natureza cognitiva, mesmo que esta essência seja infinitamente desproporcionada e não consiga chegar à natureza do objeto. Nosso intelecto multiplica relativa e reflexivamente a Divindade em três, visto que "uma coisa clara e simples se não pode imprimir noutra menos clara do que ela senão multiplicando o seu sublime brilho em diversas luzes menos fulgentes" (ABRAVANEL, 2001, pg. 293). 
0 intelecto em potência transforma a unidade em trindade porque ele é em si trino e não pode compreender a unidade sem relação trina. Isso não quer dizer que ele transforma o um em três, mas sim que ele compreende o um sob forma trina. 0 um significa "primeira forma", o dois significa "matéria primeira" e três o "primeiro ente". Da mesma maneira, o inteligente, a coisa entendida e a inteligência estão unidos quando estão em ato e são a mesma coisa, mas quando em potência estão separados e são três coisas diferentes. De modo que 0 amado, 0 amante e 0 amor são uma coisa só quando em ato e são três coisas separadas quando em potência.

Para explicar melhor a impossibilidade do intelecto em potência entender a unidade, Abravanel dá o exemplo da intelecção do fogo. 0 homem é inteligente e a natureza do fogo é coisa que ele percebe. Quando o intelecto do homem está em potência, o homem, o fogo e a inteligência do homem que percebe o fogo são três coisas separadas. Porém, quando o intelecto humano entende o fogo em ato, une-se com a essência do fogo, e é uma e a mesma coisa que aquele fogo intelectivo. Quando o intelecto está em ato não há separação entre a mente, a intelecção e a coisa.

Depois deste amor, que é incompreensível pelo intelecto em potência por ser eterno, uno, e intrínseco a Deus, vem aquele amor pelo qual o mundo foi criado. Este primeiro amor extrínseco nasceu no momento em que nasceu o universo. 0 Criador, amando a sua própria Beleza, desejou produzir um filho à sua semelhança. Este segundo desejo foi o primeiro amor que não é intrínseco à Divindade, é o amor de Deus para com o mundo produzido. Como qualquer coisa produzida e gerada, o mundo é engendrado de pai e mãe, pois a geração só pode ocorrer mediante 0 amor entre pai e mãe, este amor os une em ato gerativo. Os pais do universo criado são um com Deus. A Suma Beleza é o verdadeiro pai, o primeiro amado. A Mente divina é a primeira mãe, esta 
é a Sapiência divina, a visão divina que conhecendo a sua Beleza. Assim, pai e a mãe do mundo criado são uma só coisa com a Divindade.

Quando o primeiro amor extrínseco nasceu, deu origem a primeira criação dos primeiros pais mundanos e do próprio mundo criado. Estes pais mundanos são os dois primeiros gerados por Deus na criação do mundo. São eles o Intelecto Primeiro e o Caos. No Intelecto Primeiro resplandecem todas as Ideias do sumo Artífice, que é pai formador e engendrador do mundo. 0 Caos contém a sombra de todas as ideias, pois contém todas as essências delas, e é mãe do mundo. Estes dois foram instrumentos engendradores por meio dos quais Deus, com amor desiderativo, criou, enformou e matizou todo o universo criado a semelhança da Beleza, Sapiência ou Essência divina.

No universo criado além do amor divino, que é o primeiro extrínseco à Divindade, houve outro que foi necessário para a criação. Este amor foi o do Caos como mãe, ao Intelecto Primeiro como pai. E foi por meio deste segundo amor extrínseco que o mundo foi engendrado. Porém, existe ainda um terceiro amor extrínseco à Divindade que foi necessário na criação e no ser do mundo. Este é 0 amor que todas as partes do universo têm uma para com a outra e para com 0 todo. Todos estes três últimos amores surgiram quando nasceram os dois primeiros pais, e quando nasceu o mundo. De modo que, no primeiro início de todo o universo, surgiu o amor desiderativo de Deus pela criação do mundo à imagem de sua Beleza e Sapiência. Posteriormente, feito os dois primeiros pais mundanos, surgiu o seu amor recíproco. Depois de formado o mundo todo, com suas partes, surgiu o terceiro amor, 0 unitivo.

A primeira inteligência criada por Deus é a única que frui diretamente a visão da Causa Primeira e se une diretamente à Divindade. A visão que as outras inteligências separadas têm da 
Causa Primeira ocorre através das inteligências que estiverem acima e pelas quais foram geradas. 0 número dessas inteligências é igual ao número de orbes. Todas elas têm duas contemplações, uma que contempla a causa pela qual foi gerada e outra que contempla sua própria Beleza. Contemplando a beleza de sua causa elas geram uma próxima inteligência que lhe é inferior, porém, quando contemplam a sua própria beleza elas geram o seu orbe correspondente.

Dessa maneira, a geração dos seres no mundo inteligível e celeste ocorre de forma diferenciada após a geração da primeira inteligência, isso porque a Causa Primeira, 0 Criador, produziu a primeira inteligência por si só e diretamente, ao contemplar e amar a sua imensa Beleza. A primeira inteligência, ao contemplar e amar a Beleza de sua causa gera a segunda inteligência. Porém, quando contempla sua própria beleza gera o primeiro orbe. Com a segunda inteligência ocorre o mesmo. Por meio de suas duas contemplações, ela gera a terceira inteligência e o segundo orbe. Esse processo ocorre sucessivamente, até o mais baixo dos motores que é a inteligência do orbe da Lua. A inteligência deste último orbe, contemplando e amando a sua causa, gera 0 intelecto agente, que é a inteligência do mundo corruptível. Para Judá Abravanel este intelecto é a Alma do Mundo.

Quando a Alma do Mundo contempla a sua própria beleza, produz todas as espécies do mundo com matéria primeira. Porém, quando contempla e ama a beleza de sua causa, produz 0 intelecto humano, que é o último dos intelectos a ser criado e o único em potência. Depois, iluminando o intelecto humano, o reduz a ato. Desta maneira, o intelecto humano pode, por força do desejo e do amor, elevar-se até copular com o intelecto agente e, por meio deste, contemplar a própria Beleza divina de forma cristalina. Com esta contemplação o homem atinge a suprema felicidade com eterno deleite, este é o fim supremo de todo o universo criado. Assim, através do 
amor 0 ser humano pode contemplar a própria divindade mesmo estando no mundo corruptível. Com esta contemplação ele faz com que 0 universo retorne ao criador quando ele ativa seu intelecto. Para que isso ocorra é necessário que o ser humano seja capaz de ver a Beleza divina em sua unidade. Abravanel dedica boa parte do texto para explicar a relação entre beleza e unidade.

Por mais que vejamos a beleza nos corpos e acreditemos que a beleza que vemos é resultado da proporção de suas medidas, a Beleza por si mesma se encontra além das proporções. Se beleza fosse proporção, não deveriam existir coisas más que são proporcionadas, visto que todo belo é bom. Assim, aquilo que faz os corpos belos não é a proporção, mesmo porque a proporção é uma qualidade da matéria. A matéria é fundamento de todos os corpos do mundo corruptível, mas por si só é disforme e mãe de toda a deformidade. Todos os corpos têm alguma beleza que Ihe é dada pela forma que recebem, porém, nem todos eles são belos na mesma medida. Quanto mais fealdade material a forma é capaz de eliminar, mais belo torna o corpo que é enformado por ela. Isto porque os corpos só são belos porque a matéria deles recebeu a forma do mundo espiritual, que participou sua Beleza à matéria. Estas formas são irradiadas pelo intelecto divino e pela alma do mundo.

Quanto mais distantes da deformidade da matéria, mais as formas são belas. Um dos argumentos usados é que as formas mais belas que temos no mundo corruptível são imateriais: a Luz, a Harmonia e o Conhecimento. Se pensarmos em nossos cinco sentidos exteriores, perceberemos que a Beleza não entra em nosso ânimo através dos três que são mais materiais. A saber, o tato, o paladar e o olfato. Além disso, as maiores belezas se encontram nas partes da alma que se elevam mais em relação ao corpo. Que são a parte imaginativa, a razão intelectiva apartada 
da matéria e a mente abstrata, onde a beleza se encontra de forma mais perfeita. Desta maneira, devemos admitir que as formas em si são mais belas que os corpos por elas enformados.

As formas dos corpos naturais têm origem incorpórea e espiritual, e derivam da Alma do Mundo e do Intelecto Primeiro. Nestes dois, todas as formas existem primeiramente e com maior essência, perfeição e beleza que nos corpos isolados. Mas a graça formal também pode estar presente nas obras produzidas por mão humanas. Nesse caso, a beleza procede da mente do artífice humano e também é mais bela no intelecto humano do que no corpo que a recebeu, visto que ao passar do intelecto do artífice para o corpo moldado por ele, a ideia é desmembrada e distribuída no objeto. A beleza é maior quando está na mente porque a união engrandece qualquer beleza e perfeição. A divisão, por outro lado, a torna pequena.

Nos corpos naturais, a beleza que existe neles procede da Ideia que existe eternamente na própria mente do Criador. Dessa Beleza dependem as belezas de todo o universo produzido. Assim, a beleza dos corpos naturais não é outra coisa senão o resplendor de suas ideias. Por esse motivo, podemos entender que as Ideias são as verdadeiras belezas, graças às quais todos os corpos são belos. Elas são as noções do universo criado, pois todas as partes do universo são preexistentes no intelecto do Criador, onde estão em toda a sua perfeição. Para Judá Abravanel a existência das Ideias é evidente, isto porque a ordem do todo e das partes do mundo criado não existe por acaso. As noções do universo são necessárias para que haja esta ordem e são o que denominamos ideias.

Quando estas ideias estão derramadas por todas as partes do mundo criado, dando beleza às partes, elas são uma multidão diferenciada. Porém, quando estão no intelecto do Criador elas são unidade. Se no intelecto do Criador a verdadeira e primeira Beleza fosse apenas uma 
daquelas ideias e noções do universo, todas as outras noções já não seriam a primeira Ideia e Suma Beleza. A multiplicidade que caracteriza imperfeição no mundo criado não existe na primeira Beleza. Isso porque a imperfeição do efeito não implica em imperfeição na causa. Se o efeito fosse tão perfeito quanto a causa, ele se igualaria a causa.

0 mundo corpóreo procede do incorpóreo como o efeito procede da causa. Para entender o quanto o mundo corpóreo é menos perfeito que a sua causa, é só averiguar o quanto falta ao corpo em relação ao intelecto. A medida, a distribuição e a corrupção só se encontram no corpo e não no intelecto. Da mesma maneira não se pode dizer que a multiplicidade das partes do universo criado está nas noções ideais. 0 universo todo em suas partes é uno em si. Assim, a noção do universo, a Ideia dele que está na Mente do Criador, é una em si. Una e indivisível no Intelecto divino, esta Ideia multiplica-se idealmente nas partes do mundo causado.

A beleza de cada parte do universo participa da Beleza do todo. Pois a beleza da ideia do universo precede a beleza das ideias parceladas. Assim, mesmo que o universo tenha muitas partes diversamente essenciadas, sua ideia primeira é una. Esta ideia, como primeira e verdadeira beleza, é participada às outras ideias parcelares e as torna belas gradualmente. Mesmo que esta primeira ideia seja multiplicada em ordem para as partes essenciais do universo, nem por isso tal multiplicidade induz nela uma diversidade essencial divisível. Em si, Ela é indivisível, pura e extremamente simples. Em sua perfeita unidade ela contém a pluralidade de todas as partes do universo com toda a ordem dos seus graus. De modo que onde está uma estão todas, e o fato de serem todas não anula a unidade de cada uma.

Na mente do Criador e na primeira Ideia do universo a ideia do fogo se encontra junta com a ideia de água e ideia de simples está junta com a de composto. Assim, na ideia de cada parte

\section{Blucher}


do universo, está a ideia do universo todo. Da mesma forma, na Ideia una de todo o universo, está a ideia de cada uma de suas partes. Lá um contrário não está dividido do outro quanto ao lugar, nem é diverso quanto à essência do oponente.

Mas é bastante difícil entender como a multiplicidade no Intelecto divino é pura unidade. Abravanel diz que esta questão só pode ser compreendida com a "mente abstrata", visto que a linguagem corpórea é prejudicada pela materialidade das palavras. Para buscar um maior entendimento, ele compara o intelecto divino com o Sol. Assim como a Ideia do universo a luz do Sol é una, mas todas as cores estão contidas nela como em ideia e dela dependem. Na luz solar as cores não estão multiplicadas e divididas como estão nos corpos inferiores, na sua unidade ela contém todos os graus e diferenças de cores. Isso pode ser observado quando essa luz pura se imprime na umidade das nuvens formando o arco-íris. As cores do arco-ríris nos aparecem de tal maneira entrelaçadas que não conseguimos saber se estão juntas ou cada uma "de per si". De modo que, contendo em sua unidade todos os graus de luz e cores, a luz do Sol que é una, se representa com multiplicidade de cores e de luz nos diversos corpos separadamente. É assim que 0 intelecto do Criador imprime sua pura e belíssima Ideia no universo. Ela contém todos os graus essenciais da beleza dos corpos.

No nosso próprio intelecto essa passagem da unidade para a multiplicidade também pode ser observada. Quando um simples conceito intelectual se configura em nossa fantasia ou se conserva na memória, ele já não está em sua unidade, mas se apresenta em uma múltipla e compacta imaginação. Como emanação do conceito unitário e simples, esta imaginação se representa no nosso discurso com um grande número de palavras consideradas separadamente. Assim, na nossa fantasia ou memória permanecem representações de conceitos que são unos 
quando em nosso intelecto. De forma similar, também a luz pura do Sol está representada no arcoíris e a Beleza divina nas essências existentes nos intelectos criados.

Mas ainda não se chega a um entendimento adequado se dissermos que a Ideia do universo, ou Suma Beleza, existe propriamente no Intelecto divino, pois ela é o próprio Intelecto divino. Se a Beleza da ideia do universo, que é a Suma e Primeira Beleza fosse coisa distinta do Intelecto divino, poder-se-ia pensar que a Ideia do universo é mais bela que o próprio Intelecto do Criador. Já que a suprema Beleza seria, assim, uma intelecção d'Ele e não Ele próprio. Esta dificuldade de entendimento nasce do emprego de termos impróprios para explicar a Divindade. Como se diz que a Ideia do universo está no Intelecto ou mente divina, pensa-se que tal Ideia é coisa diferente da mente em que ela está. Isso porque pensamos que uma coisa que existe em alguém é necessariamente distinta daquele alguém em que ela existe.

Mas não só no Criador, como também em todo intelecto do universo criado que esteja em ato, a Sapiência, o Conceito e o próprio Intelecto são uma e a mesma coisa em si. De modo que, a beleza da Ideia do universo, que é a Primeira Beleza, pela qual todas as coisas são belas, é a própria Beleza do Intelecto divino. Não está nele como em sujeito, mas Ela é o próprio Intelecto divino.

A Ideia do universo, a Suma Beleza que é o próprio Intelecto divino, pode também ser entendida como o padrão pelo qual o universo foi produzido. Mas este pensamento também não nós dá um entendimento adequado. Pois, assim como a visão de que existe divisão entre 0 Intelecto e a Sapiência divina pode levar a pensarmos em alguma inferioridade n'Ele, se pensarmos que o Sumo Intelecto é o padrão para a produção do universo podemos crer que 0 universo é superior ao Intelecto divino, já que o fim do Intelecto divino seria produzir o universo.

\section{Blucher}


Porém, quando se diz que a Mente ou Intelecto divino é o padrão pelo qual foi produzido 0 universo, não significa que Ele tenha sido como colocado como instrumento para produção daquilo que é feito por Ele. Mas que sendo Ele perfeitíssimo, o universo todo promana d'Ele, à sua semelhança, como sua imagem. De modo que Ele é mais excelente que o universo criado na mesma media que uma pessoa verdadeira é mais excelente que sua imagem no espelho e que a luz é mais excelente que a sombra que lhe é correlativa.

A beleza da Suma Sapiência é una, pura e simples. Quando esta Beleza se derrama na criação ela torna belo tudo e cada uma das partes do universo, mas se distancia da unidade e pureza do Criador. Não existe outra beleza a não ser esta, a Suma Beleza. Ela existe participável ou participada, é produtora ou produzida. Quando na mente de Deus está puríssima e sumamente una. Porém, quando participada na criação é derramada extensa, repartida e multiplicada.

Para Abravanel, o Sumo Deus não é a Suma Beleza, a primeira Ideia do Universo. Pois Ele mesmo não é algo que se possa chamar de Beleza, mas sim a primeira origem da Beleza, é a fonte, 0 manancial de onde brota a Primeira Beleza e a Suma Sapiência. De modo que se pode falar de três graus de Beleza: a do obreiro, a Beleza em si, e a Beleza daquilo que participa dela. Há, então, o Belo belificante que é o pai da Beleza, o Sumo Deus. Há também a Beleza em si, a Suma Beleza que é o Primeiro Intelecto Ideal. Após estas duas, há o Belo belificado, o universo criado, que é 0 filho da Beleza.

A Beleza é aquilo que causa graça naquele que a vê. Assim, a Beleza deve ser visível pelos olhos do corpo ou do espírito. Nenhuma vista intelectual do mundo criado pode ver além da Sapiência divina. Pelo conhecimento da Sapiência divina se sabe que ela tem um princípio, mas este princípio não é algo que se possa ver ou que se possa classificar como Beleza. Os olhos do 
intelecto não podem conhecer além da Suma Beleza e Sapiência, mas podem saber que há o Sumo Belo e sapiente, que é manancial dela.

Na obra Diálogos de Amor, os amores do mundo criado estão ordenados e hierarquizados de maneira idêntica aos graus de ser do universo. Abravanel entende que é o amor que causa tanto da criação do universo quanto do retorno da criação ao Criador. 0 amor é a causa de todos os "elos" entre os graus superiores e inferiores de seres e entre os três mundos que compõem sua cosmologia.

0 mais belo infunde sua perfeição e participa sua beleza o tanto quanto possível ao menos belo. Assim, o amor vem descendo do Sumo Opífice ao longo dos graus de seres. Cada um dos seres, com amor paterno e produtivo, causa a produção de seu sucessivo inferior. Do mundo angélico para o mundo celeste, ambos de grau em grau. 0 mundo celeste, com amor paterno, produz o mundo corruptível por meio da matéria primeira.

0 amor do maior ao menor é o meio e a causa da produção. A deleitação decorrente do amor do superior pra o inferior consiste em unir-se com o não belo belificando-o ou o tornando perfeito ao participar-Ihe sua beleza. Isto proporciona perfeição deleitável não só ao efeito, que é inferior, como também à causa pela relação com seu efeito. 0 efeito belo e perfeito torna sua causa mais perfeita, mais bela e deleitável."A árvore frutifera é sempre mais bela que a estéril, e as águas que brotam e correm para fora [da nascente] são mais recomendáveis do que as represadas e estagnadas entre seus diques" (ABRAVANEL, 2001, pg. 410).

Quando o amor se dá do menos belo para o mais belo, o objetivo é conseguir um pouco de sua beleza e unir-se a ela. Isso ocorre de grau em grau até a união da natureza intelectiva criada com o Sumo Bem, mediante o último e mais perfectivo amor. Este último amor da natureza

\section{Blucher}


intelectiva criada é a causa do ato unitivo do universo com o seu Criador e a causa de sua suprema perfeição. Os amores produtivos da criação se dirigem aos amores recondutivos do retorno. Todos os amores recondutivos se orientam sucessivamente para o último amor, que leva ao supremo ato unitivo do universo com o Sumo Bem, que é a sua perfeição extrema.

0 cosmos de Abravanel é uma sucessão de entes que se "acomodam" em posições superiores ou inferiores de acordo com a amplitude de sua visão da Beleza. É o grau de sua visão da Suma Beleza que determina a posição do ente na hierarquia de seres do universo, pois quanto maior é sua visão, maior é o seu conhecimento da Beleza e, portanto, maior o seu amor. A medida do seu amor é também a medida de seu deleite ao ter contato com a Beleza, pois quanto maior é a beleza que a visão do ser alcança, mais deleite tem como resultado da copulação com ela. Mesmo o Criador busca o deleite, pois a copulação com sua própria Beleza resulta em deleite, e dessa copulação é gerado o universo como imagem perfeita d'Ela.

0 universo de Abravanel é pensado como um ente uno, que tem a função de refletir a Beleza de Deus e é semelhante a Ela. A Beleza divina é o que dá forma ao universo, não só ao universo pensado como unidade, mas também a todas as partes dele. 0 universo é um ente que tem uma Forma, uma Essência, uma Ideia. Todos os entes têm uma forma, que é ao mesmo tempo sua essência, sua ideia e sua beleza. Mas a essência do universo como um ente, o que dá forma e unidade a ele, é a própria Beleza do Criador, que é infinita e eterna. Já as partes do universo, que são os seres que o compõem, têm, cada uma delas, uma parcela finita dessa Beleza.

Toda a ligação entre as diversas partes do universo, é direta ou indiretamente causada pelo desejo da Suma Beleza, que é a Ideia do universo e dá unidade a ele. Assim, quando todos os seres desejam a Suma Beleza, estão desejando e amando, ao mesmo tempo, a unidade do 
universo e colaborando para ela. Desta maneira, Judá Abravanel transforma toda a ligação entre os entes do universo em ligação amorosa, uma ligação de amor por beleza. Todos os seres têm uma forma que é ao mesmo tempo sua beleza e sua essência. Além disso, todas as belezas do universo são, de forma participada, a Suma Beleza. De modo que há uma identidade entre a beleza de uma pedra e a beleza da Inteligência Primeira. Nessa cosmologia todo o amor é desejo de beleza e toda a beleza é, mesmo que de forma participada, a Suma Beleza de Deus, que Ele participou ao universo, em menor ou maior grau para cada uma das partes.

Todo o universo criado tem a dualidade necessária para que ocorra um nascimento. $\mathrm{Na}$ linguagem do texto, tudo o que é gerado necessita de pai e mãe. Assim, todo o universo, composto de três mundos, é resultado da união de dois princípios. Mesmo a Inteligência Primeira, que contém todas formas do universo e não têm composição material, foi resultado da copulação do Criador com sua própria Beleza. Para Abravanel impossibilidade de conceber a unidade entre 0 Criador e sua Beleza é decorrente das deficiências do intelecto humano.

A diferença entre unidade e multiplicidade é também de grande importância para entender o processo de criação, mesmo no mundo dual. Toda a criação, inclusive a humana, ocorre após a visão de uma ideia que é una e torna-se múltipla com o labor daquele que cria.

\section{Referências bibliográficas:}

ARISTÓTELES. Do Ceu. Trad: Edson Bini. São Paulo: Edipro, 2014

BÍBLIA HEBRAICA. . Trad: David Gorodovits e Jairo Fridlin. São Paulo: Sêfer, 2006. 
CARVALHO, Joaquim. Historia e Historia da Filosofia. Disponível em: http://www.joaquimdecarvalho.org/artigos/artigo/22-Capitulo-II-A-obra-de-Leao-Hebreu- - Acesso em: 11 mai. 2017.

HEBREU, Leão. Diálogos de Amor. Tradução de Giacinto Manuppella. Lisboa: Ed. Imprensa Nacional-Casa da Moeda, 2001.

MAIMONIDES, Moises. Guia dos Perplexos, parte 2. Trad. Uri Lan. São Paulo: Ed. Landy, 2003.

PLATÃo. Banquete. Trad. José Cavalcante de Souza. São Paulo: ed. Abril Cultural, 1972.

REALE, Giovanni. Historia da Filosofia. Volume I. Ed. Paulus, São Paulo, 1990.

VILA-CHÃ, J. J. Leão Hebreu e o significado da sua obra. In: HEBREU, Leão. Diálogos de Amor. Tradução de Giacinto Manuppella. Ed. Imprensa Nacional-Casa da Moeda, Lisboa, 2001, 9 p. 